\title{
Atypical Presentations of Spinal Cord Tumors in Children
}

\author{
Patricia L. Robertson, MD
}

\begin{abstract}
Pain is a frequent presenting symptom of spinal cord tumors in children and usually manifests as local spinal pain in the bony segments overlying the tumor. Two pediatric patients are presented in whom the diagnosis of intramedullary spinal cord tumors was delayed for many months because their pain was atypical. One had recurrent abdominal pain diagnosed as irritable bowel syndrome. The other had very abrupt paroxysmal but infrequent attacks of arm pain and no neurologic abnormalities. Possible mechanisms of their pain, as well as the other features that might have suggested the diagnosis, are discussed. (J Child Neurol 1992;7:360-363).
\end{abstract}

$\mathrm{P}$ Dain is a frequent early presenting symptom in children with intramedullary spinal cord tumors. ${ }^{1,2}$ Initially, it may not be accompanied by any other symptoms or signs of neurologic dysfunction. The pain of intramedullary cord tumors is most commonly and characteristically local spinal pain that occurs along the spinal axis in the bony segments overlying the tumor. It manifests as back pain when it involves thoracic or lumbar segments and as neck pain with cervical localization. We report two pediatric patients with atypical pain syndromes, in whom the diagnosis of intramedullary spinal cord tumors was delayed for many months. These cases illustrate the importance of including spinal cord tumors in the differential diagnosis of children who have a broader spectrum of pain symptoms than is considered characteristic of these tumors.

\section{Case Reports}

\section{Case 1}

A $31 / 2$-year-old boy was seen because of chronic periumbilical abdominal pain for 1 month. The pain was intermittent, with episodes occurring almost daily and lasting $30 \mathrm{~min}-$ utes to several hours. The pain episodes occurred during

Received Feb 10, 1992. Received revised April 2, 1992. Accepted for publication April 8, 1992.

From the Departments of Pediatrics and Neurology, University of Michigan, Ann Arbor, MI.

Address correspondence to: Dr Patricia L. Robertson, University of Michigan Medical School, Division of Pediatric Neurology, R6060 Kresge II, Box 0570, 171 Zina Pitcher Place, Ann Arbor, MI 48109-0570. the day, but they also frequently awakened the child from sleep. He had no fever, nausea, vomiting, diarrhea, or dysuria. His height and weight were appropriate for his age, and the rest of his physical examination was normal, although the details of the neurologic examination were not noted. Laboratory evaluations revealed hemoglobin, 13.3 $\mathrm{g} / \mathrm{dL}$; white blood cell count (WBC), $5700 / \mathrm{mm}^{3}$; platelet

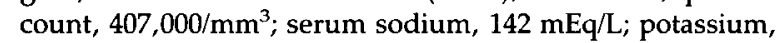
$5.7 \mathrm{mEq} / \mathrm{L}$; chloride, $105 \mathrm{mEq} / \mathrm{L}$; urea nitrogen, $6 \mathrm{mg} / \mathrm{dL}$; creatinine, $0.1 \mathrm{mg} / \mathrm{dL}$; aspartate aminotransferase (AST), 21 $\mathrm{IU} / \mathrm{L}$; alanine aminotransferase (ALT), $22 \mathrm{IU} / \mathrm{L}$; amylase, 34 $\mathrm{IU} / \mathrm{L}$; lipase, $11 \mathrm{IU} / \mathrm{dL}$; and Westergren erythrocyte sedimentation rate, $12 \mathrm{~mm} /$ hour. All of these were normal as was a routine urinalysis and an upper gastrointestinal tract study. The child was diagnosed as having probable irritable bowel syndrome. A high-fiber diet, mineral oil, heating pad application, and analgesics were prescribed, which resulted in no improvement over a 4- to 5 -month period. The pain episodes then began to last longer, and the child began to walk in a stooped position, bent over stiffly from the waist. He was reevaluated when he also developed a head tilt. At that time, a thoracic scoliosis was noted, along with mild lower extremity loss of vibration and position sense, hyperreflexia, and Babinski signs. Magnetic resonance imaging (MRI) scan of his cervical and thoracic spine revealed a contrast-enhancing intramedullary tumor extending predominantly from the 6 th to the 10 th thoracic segment, with tumor-associated cysts up to the 4 th cervical segment (Figure 1). This was confirmed pathologically as a high-grade astrocytoma. Surgical decompression and partial resection of the tumor relieved the abdominal pain. The child subsequently underwent radiation and chemotherapy for the tumor.

\section{Case 2}

A 21/2-year-old boy was seen because of right arm pain of 6 months' duration. The episodes began abruptly with a sudden backward jerk of his right arm, after which he would 


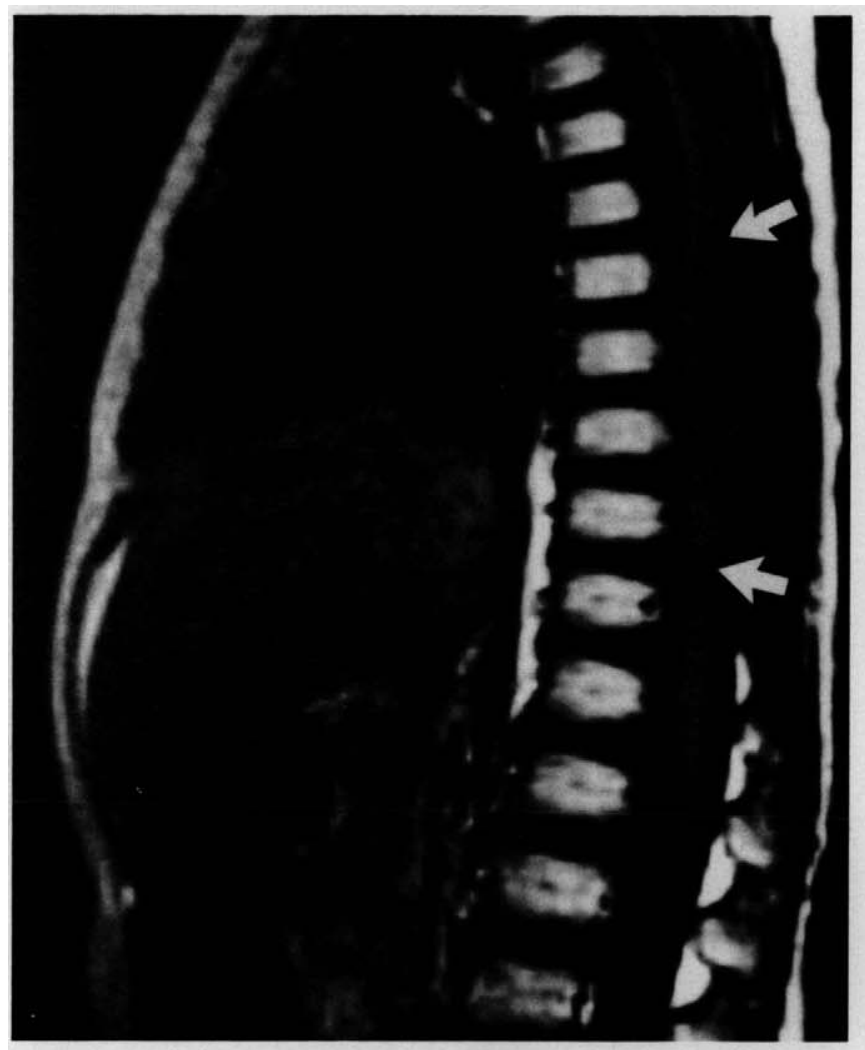

Figure 1A

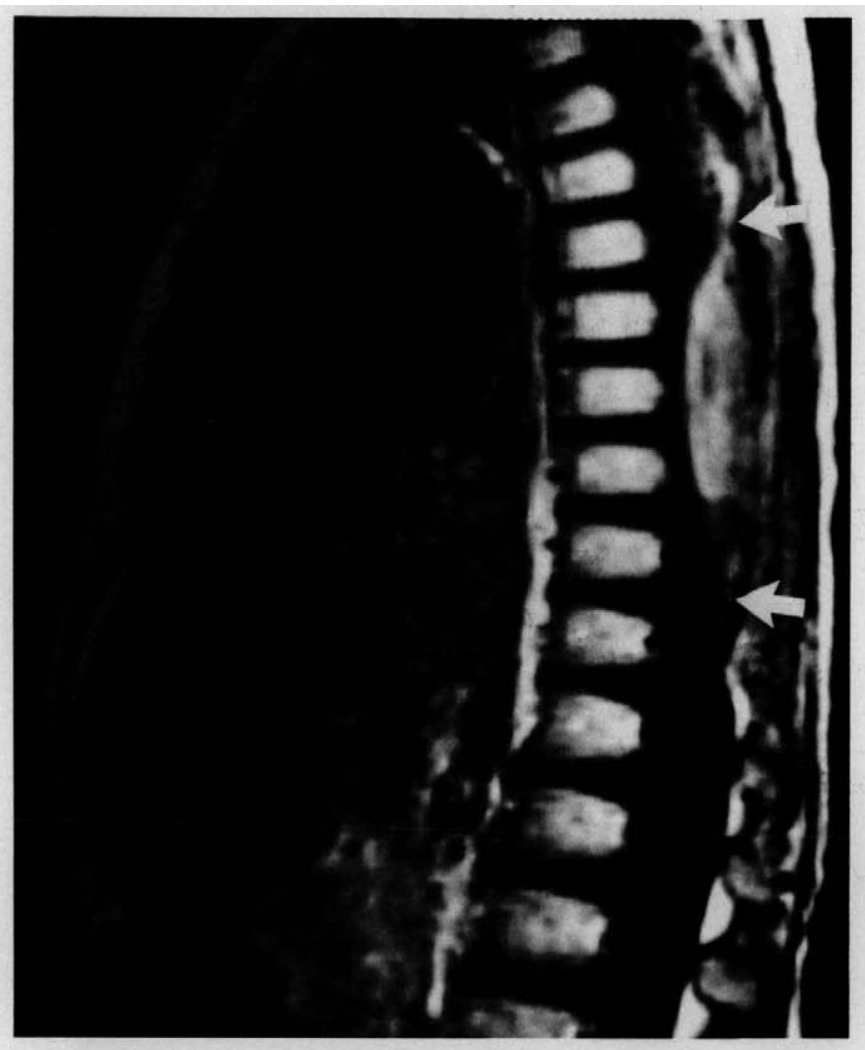

Figure 1B

\section{FIGURE 1}

$\mathrm{T}_{1}$-weighted magnetic resonance images $(\mathrm{TR}=567 \mathrm{~ms} ; \mathrm{TE}=20 \mathrm{~ms}$ ) of the intramedullary thoracic glioma of the child in case 1. A. Without contrast, showing tumor within the cord, predominant between T6 and T10 (arrows). B. With contrast, showing tumor enhancement; tumor-associated cysts can be seen above the top arrow.

lie down holding his arm, sometimes crying until the pain stopped 1 to several hours later. The attacks ended as abruptly as they began, and he would then resume his normal activities. There was no alteration of consciousness or urinary incontinence associated with these attacks, and afterward he talked about the pain being "like a hammer hitting him" in the arm. He remained completely symptom free between attacks, which were occurring at 3- to 6-week intervals.

Initial physical examination, including a detailed neurologic examination, revealed no abnormalities. Radiographs of his right clavicle, shoulder, arm, elbow, and forearm were normal. Laboratory studies revealed hemoglobin, $12.3 \mathrm{~g} / \mathrm{dL}$; WBC, $7300 / \mathrm{mm}^{3}$; platelet count, 289,000 / $\mathrm{mm}^{3}$; serum sodium, $140 \mathrm{mEq} / \mathrm{L}$; potassium, $4.2 \mathrm{mEq} / \mathrm{L}$; chloride, $108 \mathrm{mEq} / \mathrm{L} ; \mathrm{CO}_{2}, 23 \mathrm{mEq} / \mathrm{L}$; urea nitrogen, $13 \mathrm{mg} /$ $\mathrm{dL}$; creatinine, $0.4 \mathrm{mg} / \mathrm{dL} ; \mathrm{ALT}, 35 \mathrm{IU} / \mathrm{L} ; \mathrm{AST}, 20 \mathrm{IU} / \mathrm{L}$; uric acid, $2.6 \mathrm{mg} / \mathrm{dL}$; and Westergren erythrocyte sedimentation rate, $9 \mathrm{~mm} / \mathrm{hour}$, all of which were within the normal range. Somatosensory evoked responses after median nerve stimulation were normal bilaterally, as were nerve conduction studies and needle electromyography in the right arm.

The child continued to have the pain attacks for several months. They were lasting somewhat longer and were no longer heralded by the arm jerks but were occurring with no greater frequency. He complained of no new symptoms either during or between attacks, and his examination was still normal 6 weeks and 3 months later. Because of the very paroxysmal nature of the attacks, the possibility was considered that the episodes were a type of sensory seizure. Attempts were made to see the child and obtain an electroencephalogram during an attack, but logistic problems prevented this for several more months. Finally, more than a year after his symptoms began, he had begun to have occasional urinary incontinence, and his examination revealed mild lower extremity hyperreflexia. MRI scan of his cervical and thoracic spine at that time confirmed the presence of an intramedullary tumor that extended from the 5th cervical to the 4th thoracic segment (Figure 2) and proved to be a low-grade astrocytoma on pathologic examination. His arm pain resolved after decompressive laminectomy and resection of the tumor. He subsequently underwent radiation therapy for the tumor.

\section{Discussion}

Recurrent abdominal pain, like that seen in case 1 , is a very common pediatric complaint, occurring in an 
estimated $10 \%$ of children, ${ }^{3}$ but the syndrome is only infrequently caused by organic disease. Although a child with back or neck pain quickly brings to mind pathologic processes of the vertebral column, including the spinal cord, the organic disorders more likely to be considered in a child with recurrent abdominal pain are those involving the gastrointestinal or genitourinary systems. When these processes are excluded on the basis of history, examination, and further testing when indicated, a functional basis for the pain is often assigned, as it was in this child.

Case 1 demonstrates that recurrent abdominal pain can be the presenting symptom of a spinal cord tumor, and it has been described in a few other children. ${ }^{4-6}$ The pain in case 1 may have been of radicular origin from the 8 th to the 10 th thoracic segmental nerve roots of the tumor-affected spinal cord, which supply the abdominal wall. Radicular pain is reported in children with spinal-cord tumors although it is much less frequent than spinal pain localized to the bony segments overlying the tumor, which would have caused back pain in this child. ${ }^{2}$ It is also possible that this child's symptoms were referred pain from irritation by the tumor of spinalcord nerve fiber tracts that supply the abdominal viscera.

Obviously, not every child with recurrent abdominal pain should have imaging studies performed to rule out a spinal cord tumor. However, this case illustrates several points about how children with this serious, though uncommon, cause of abdominal pain might be identified more promptly. The nocturnal occurrence of this child's pain was an overlooked clue to organic disease. Functional abdominal pain rarely awakens a child from sleep. ${ }^{3,4}$ Moreover, pain associated with spinal cord tumors is typically worse in the recumbent position, when venous congestion further distends the dura and produces characteristic nighttime pain. ${ }^{1,6}$

When this child was initially seen, no signs suggesting spinal cord involvement were noted. But unless a careful neurologic examination is performed with this possibility specifically in mind, subtle findings such as mild weakness, reflex changes, sensory changes, or rectal tone abnormalities that would help support the diagnosis could be easily missed. Scoliosis, also present in this child, is another finding that should raise suspicion of a spinal cord problem, and it should be looked for in a child with recurrent abdominal pain. ${ }^{4}$

The child in the second case posed a different diagnostic problem. Pain in the extremities is also a

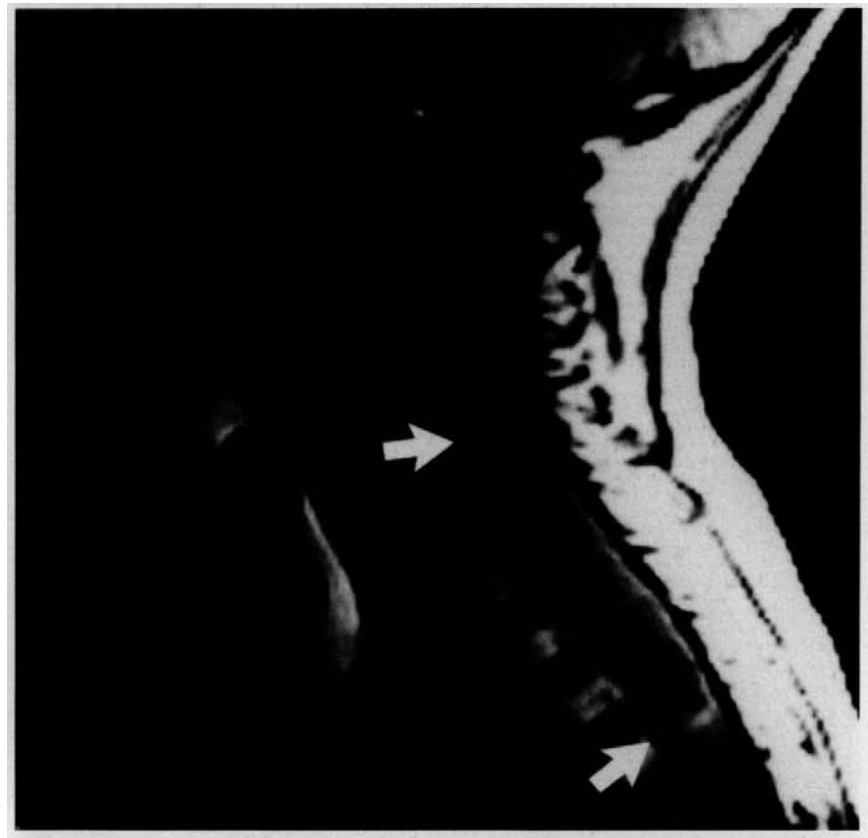

Figure 2A

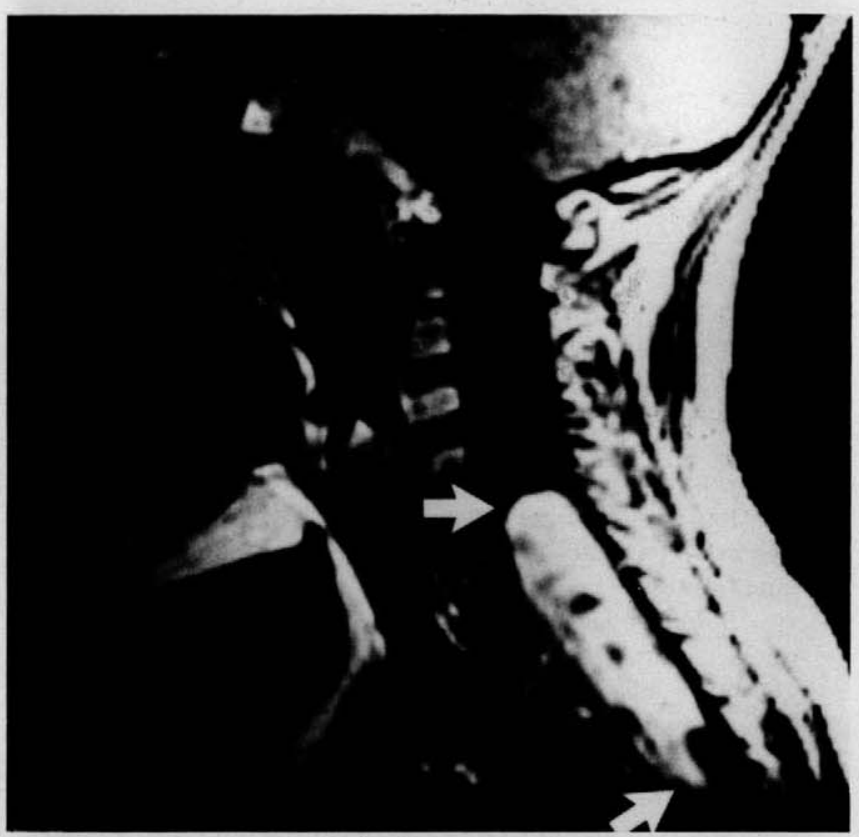

Figure 2B

\section{FIGURE 2}

$T_{1}$-weighted magnetic resonance images $(T R=600 \mathrm{~ms}$; $\mathrm{TE}=20 \mathrm{~ms}$ ) of the intramedullary cervicothoracic glioma of the child in case 2. A. Without contrast, showing tumor within the cord between C5 and T4 (arrows), with tumorassociated cyst above, extending to upper cervical levels. B. With contrast, showing tumor enhancement. 
fairly common pediatric symptom and was the presenting complaint in $7 \%$ of pediatric office visits in one study. ${ }^{7}$ Here again, a serious underlying pathologic condition is absent in most children with this symptom. ${ }^{8}$ With limb pain, the major focus in evaluating for possible organic causes is on the musculoskeletal system, including traumatic, orthopedic, infectious, rheumatologic, or neoplastic processes involving bone, joint, or muscle.

Although limb pain caused by nerve or nerve root involvement is not common in children, as noted already, radicular pain can be the presenting symptom in some children with intramedullary spinal cord tumors, ${ }^{1}$ and cervical root involvement was very likely the cause of the pain in this child. Whether radicular pain associated with intramedullary spinal cord tumors originates from peritumoral edema extending to the nerve root or from actual infiltration of the root by tumor is uncertain. ${ }^{9}$ In this case, the relatively long periods between pain episodes suggested that tumor-associated edema, which would have more potential for variability from day to day, would be the more likely explanation. The mechanism of the jerks that initially heralded the attacks is also unclear. Segmental myoclonus is a possibility, although in most reported cases associated with spinal cord tumors, the movements are repetitive, rhythmic, and more continuous than those seen in this case. ${ }^{10}$

An incorrect interpretation of several findings in case 2 contributed to the delay in making the diagnosis. Organic disease was correctly suspected in this child because of the severity of his pain, interrupting his play, and its constancy in the same location with each attack. However, after the more usual musculoskeletal causes were ruled out, cervical nerve involvement, either at the root or in the brachial plexus, was considered but then rejected because of the normal neurologic examination, somatosensory evoked responses, and electrophysiologic studies. The long periods between pain epi- sodes, during which he was completely free of symptoms, made the likelihood of a neoplasm involving nerve roots seem remote as well. These conclusions proved to be wrong and delayed obtaining the definitive studies.

Case 2 emphasizes that limb pain in a child, when severe and in a consistent location, even if it is very intermittent, should be taken as a sign of a serious pathologic condition. When it is not explained readily by injury or other identifiable disease, the possibility of a spinal cord tumor must be considered. Although abnormal neurologic findings are helpful in suggesting the diagnosis and should be looked for carefully, as this case demonstrates, neither a normal examination nor electrophysiologic studies correctly excluded it. This points to the need for continued very close follow-up of such a child until a definite diagnosis is made.

\section{References}

1. Epstein F: Spinal cord astrocytomas of childhood. Prog Exp Tumor Res 1987;30:135-153.

2. Reimer R, Onofri BM: Astrocytomas of the spinal cord in children and adolescents. J Neurosurg 1985;63:669-675.

3. Olson A: Recurrent abdominal pain: An approach to diagnosis and management. Pediatr Ann 1987;16:834-836.

4. Buck E, Bodensteiner J: Thoracic cord tumor appearing as recurrent abdominal pain. Am J Dis Child 1981;135:574-575.

5. Eeg-Olofsson O, Carlsson E, Jeppsson S: Recurrent abdominal pains as the first symptom of a spinal cord tumor. Acta Paediatr Scand 1981;70:595-597.

6. Drexler DL, Grill BB, Ashwal S: Spinal cord tumor-associated syrinx mimicking abdominal epilepsy. I Pediatr Gastroenterol Nutr 1989;9:524-527.

7. Stern WE: Localization and diagnosis of spinal cord tumors. Clin Neurosurg 1978;25:480-494.

8. Bowyer SL, Hollister JR: Limb pain in childhood. Pediatr Clin North Am 1984;31:1053-1081.

9. Epstein F, Epstein N: Intramedullary tumors of the spinal cord, in Shillito J Jr, Matsen DD (eds): Pediatric Neurosurgery: Surgery of the Developing Nervous System. New York, Grune \& Stratton, 1982, pp 529-539.

10. Nohl M, Doose H, Gross-Selbeck G, Jensen HP: Spinal myoclonus. Eur Neurol 1978;17:129-135. 